\title{
The kinetic friction of saline ice against itself at low sliding velocities
}

\author{
D.E. Jones, F.E. Kennedy And E.M. Schulson \\ Thayer School of Engineering, Dartmouth College, Hanover, New Hampshire 03755, U.S.A.
}

\begin{abstract}
An experimental investigation was performed on the kinetic friction coefficient of laboratory-grown, columnar saline ice sliding against itself. Tests were performed on a dual-opposing load apparatus specially manufactured for attachment to an MTS testing system. The mean kinetic friction coefficient, $\mu$, was measured for sliding velocities from $10^{-6}$ to $5 \times 10^{-2} \mathrm{~m} \mathrm{~s}^{-1}$ at temperatures from $-3^{\circ}$ to $-40^{\circ} \mathrm{C}$ under a contact pressure of about $20 \mathrm{kPa}$. The ice specimens were oriented with grain columns perpendicular to the sliding interface. At $-3^{\circ} \mathrm{C}$ and at $-10^{\circ} \mathrm{C}$, three distinct regions were observed: from $10^{-6}$ to about $10^{-5} \mathrm{~m} \mathrm{~s}^{-1}, \mu$ was nearly constant at 0.5 ; at velocities from $10^{-5}$ to $10^{-3} \mathrm{~m} \mathrm{~s}^{-1}, \mu$ began to drop rapidly to about 0.1 ; and, above $10^{-3} \mathrm{~m} \mathrm{~s}^{-1}, \mu$ began to level off at $\sim 0.05$. The velocity at which $\mu$ began to decline increased with decreasing temperature. At temperatures below $-10^{\circ} \mathrm{C}, \mu$ increased from $\sim 0.5$ at $v=10^{-6} \mathrm{~m} \mathrm{~s}^{-1}$ to a peak value of $\sim 0.7$ near a velocity of $5 \times 10^{-5} \mathrm{~m} \mathrm{~s}^{-1}$ and then fell rapidly to about 0.1 at $10^{-2} \mathrm{~m} \mathrm{~s}^{-1}$. In general, $\mu$ increased with decreasing temperature and sliding velocity.
\end{abstract}

\section{INTRODUGTION}

The kinetic friction coefficient of ice sliding against itself is important in sea-ice ridge building (Hopkins and Hibler, 1989) and in the brittle compressive fracture (Schulson, 1990) of the material. Despite its importance, the topic has not yet been extensively studied, especially at low velocities. In both applications, the sliding velocities are quite low $\left(<0.1 \mathrm{~m} \mathrm{~s}^{-1}\right)$. Earlier work on fresh-water ice (Barnes and others, 1971) showed that large changes in ice friction occur in the $10^{-5}$ to $10^{-2} \mathrm{~m} \mathrm{~s}^{-1}$ velocity range. This paper considers the effects of temperature $\left(-3^{\circ}\right.$ to $\left.-40^{\circ} \mathrm{C}\right)$ and sliding velocity $\left(10^{-6}\right.$ to $\left.5 \times 10^{-2} \mathrm{~m} \mathrm{~s}^{-1}\right)$ on the friction coefficient, defined as the ratio of the tangential force resisting sliding to the force applied normal to the plane of sliding.

\section{EXPERIMENTAL DESIGN}

Ice was manufactured according to general procedures developed at the Thayer School of Engineering Ice Research Laboratory (Kuehn and others, 1988). The test material was grown from water of 20 parts per thousand (ppt) salt concentration (obtained using "Instant Ocean", a commercial product recreating the composition of ocean water) which was contained within a 10001 insulated tank. Heat was removed unidirectionally through a cooling plate, producing a puck of ice approximately $1 \mathrm{~m}$ in diameter and up to $0.35 \mathrm{~m}$ in
Table 1. Characteristics of the test ice and first-year sea ice (Kuehn and others, 1988)

Lab-grown saline ice First-year sea ice

$\begin{array}{rlc}\text { Salinity (ppt) } & 4.3 \pm 0.2 & \\ \quad \text { Nov. 1984 } & & 4.3 \pm 0.3 \\ \text { Apr. 1983 } & & 4.2 \pm 0.4 \\ \text { Density }\left(\mathrm{kg} \mathrm{m}^{-3}\right) & 914 \pm 3 & - \\ \text { Platelet spacing (mm) } & 0.5-1.0 & 0.5-1.0 \\ \text { Grain size (mm) top } & 1.6 \pm 0.3 & \\ \text { middle } & 3.9 \pm 0.6 & 4.2 \pm 0.6 \\ \text { bottom } & 5.2 \pm 0.5 & \end{array}$

$c$ axis randomly oriented within plane of block

thickness. The ice was columnar (Fig. 1), and similar in characteristics ( $c$-axis orientation, salinity, brine pocket sizes) to first-year sea ice (Table 1).

Blocks of two sizes, 50 by 50 by $20 \mathrm{~mm}^{3}$ and 70 by 220 by $20 \mathrm{~mm}^{3}$ were machined from the puck, with columns perpendicular to the sliding surfaces. Prior to every test, the mating surfaces were each re-surfaced using a Leitz 1400 Sledge Base Microtome to a depth of approximately 

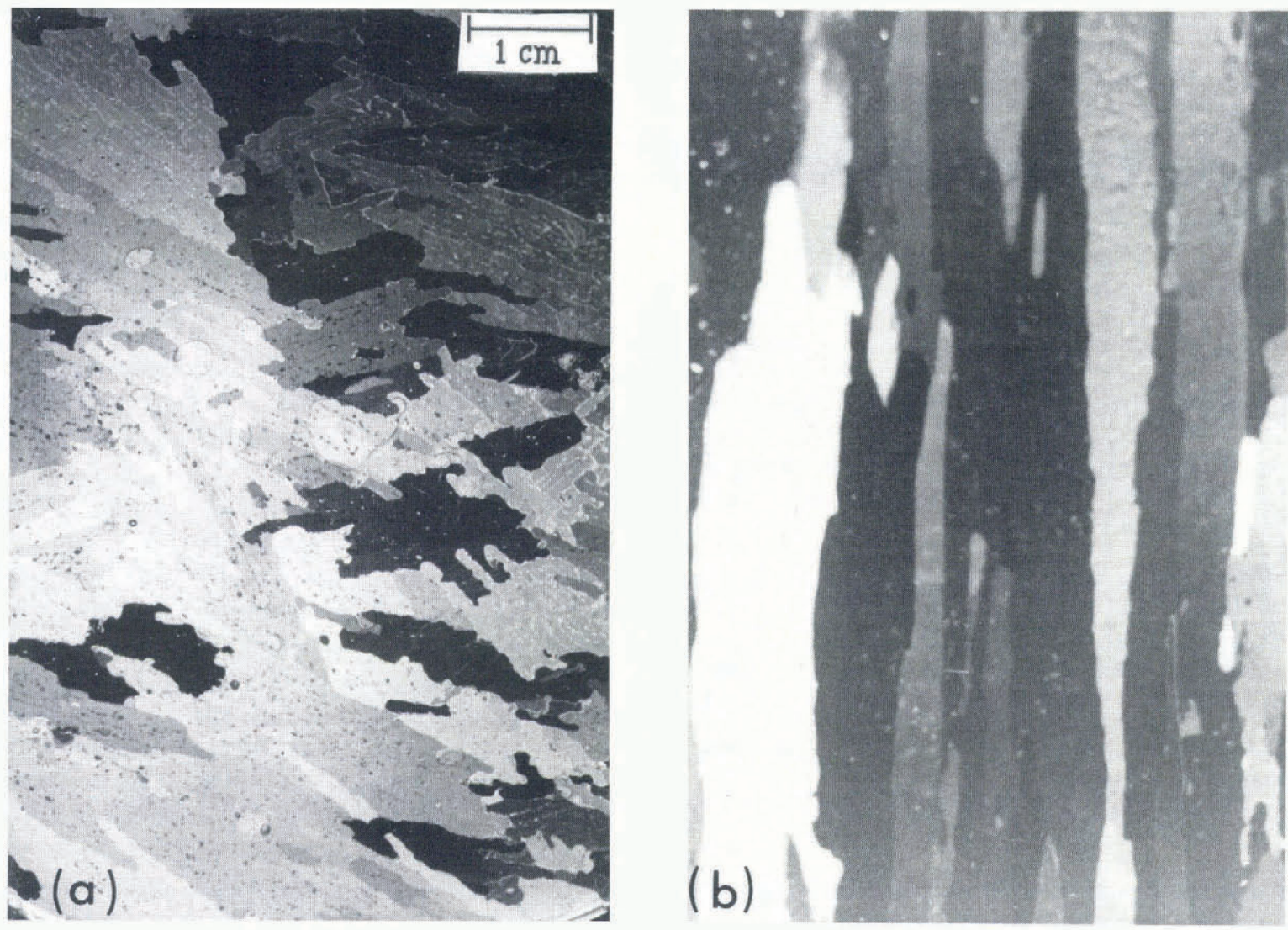

Fig. 1. Horizontal (a) and vertical (b) sections of laboratory-grown saline ice.

$1.25 \mathrm{~mm}$. Additionally, the edges of the smaller blocks were bevelled with a razor blade to remove any sharp corners which might otherwise plow into the surfaces of the larger blocks. The process was followed to create clean and fresh test surfaces, which would exhibit test traces independent of previous test runs.

To perform the testing, an attachment to a uniaxial Material Testing System (MTS) testing machine was constructed to provide a pair of balanced, opposing test surfaces. The apparatus is shown in Figure 2. The larger ice specimens $(220 \mathrm{~mm}$ long) were bonded to aluminum

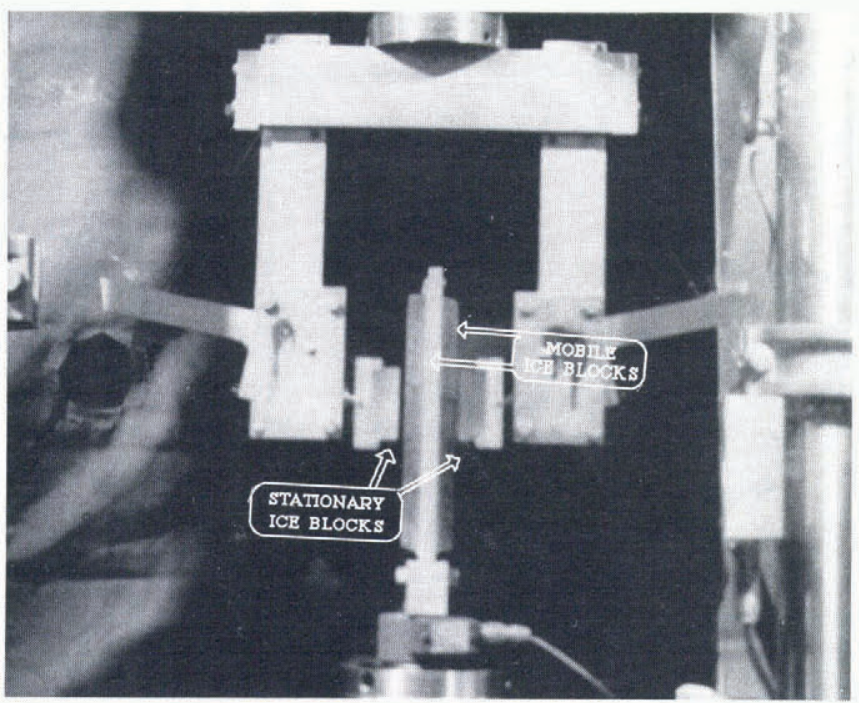

Fig. 2. Friction coefficient apparatus with stationary and mobile ice blocks. plates attached to a sensitive load transducer which measured the friction force. The load cell was mounted to the MTS hydraulic actuator, which was programmed to provide the desired sliding velocity. In contact with the two larger ice blocks were the laterally-loaded smaller, stationary ice blocks. The loading mechanisms were connected to the stationary cross-piece of the MTS testing machine.

A test constituted a single pass of the opposing block and slab faces, loaded under $17.8 \mathrm{kPa}$. The data were collected by two methods: (a) load, displacement and elapsed time were recorded using a data acquisition program, ASYST; and (b) the frictional force was plotted versus the sliding distance. The data were combined to obtain the mean and the variance of the steady-state kinetic friction coefficient for a given test. For each condition, at least four tests were performed and the averages obtained.

\section{RESULTS}

The majority of the tests was characterized, to some extent, by "stick-slip". This occurred when the opposing surfaces were held in contact temporarily until the tangential forces were sufficiently great to release the surfaces. On the traces of force versus test-time (Fig. 3), the stick-slip condition appeared as a sawtooth. Stick-slip was observed in all tests at sliding velocities $\geqslant 5 \times$ $10^{-5} \mathrm{~m} \mathrm{~s}^{-1}$, and in the tests at $-3^{\circ} \mathrm{C}$ at velocities as low as $10^{-5} \mathrm{~m} \mathrm{~s}^{-1}$. At these lowest velocities, the variation (given as the standard deviation) in the friction coefficient owing to 


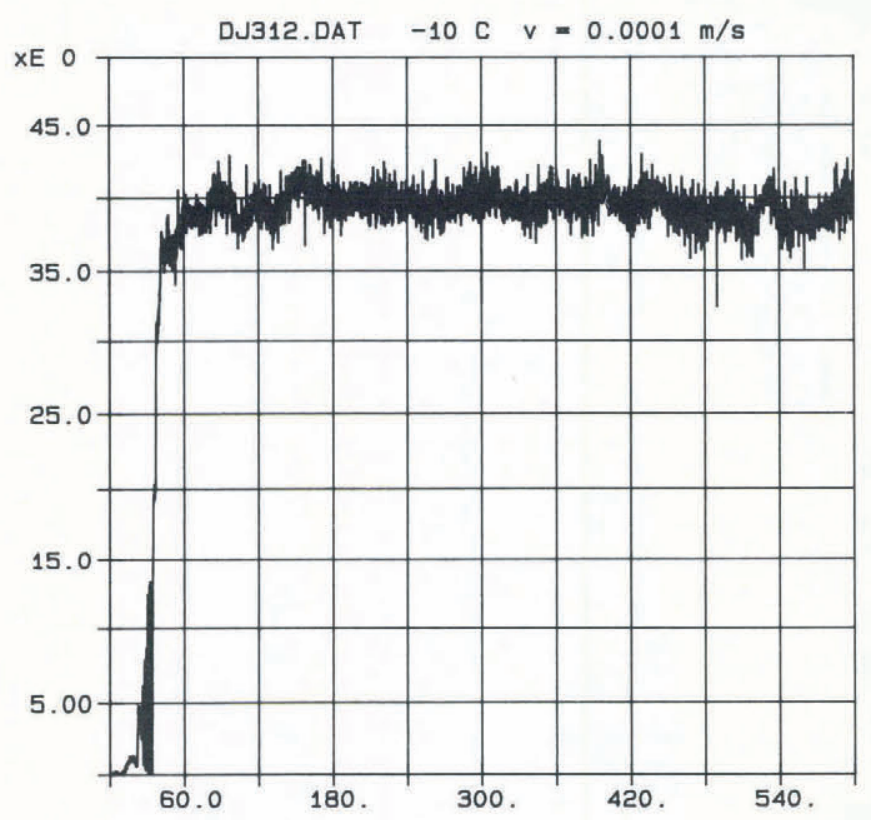

Fig. 3. Force (newtons) versus time (s) test trace, illustrating "stick-slip".

stick-slip was about one-twentieth of the mean, compared with the variation at the higher velocities $\left(\sim 10^{-3} \mathrm{~m} \mathrm{~s}^{-1}\right)$, which was about one-fifth of the mean.

Figure 4 shows the mean kinetic friction coefficient, $\mu$, versus the sliding velocity, at each of the four temperatures investigated. The standard deviations are depicted by the error bars. Two points are noteworthy. (i) The curves at $-10^{\circ}$ and $-3^{\circ} \mathrm{C}$ display three regions: the first is from $10^{-6} \mathrm{~m} \mathrm{~s}^{-1}$ to about $10^{-5} \mathrm{~m} \mathrm{~s}^{-1}$, where $\mu$ is approximately constant at $\sim 0.5$; the second region is from about $5 \times 10^{-5} \mathrm{~m} \mathrm{~s}^{-1}$ to about $10^{-3} \mathrm{~m} \mathrm{~s}^{-1}$, where $\mu$ decreases rapidly; and the third is for velocities $\geqslant 10^{-3} \mathrm{~m} \mathrm{~s}^{-1}$, where $\mu$ tends to level off at $\leqslant 0.1$. At $-20^{\circ} \mathrm{C}$ and at $-40^{\circ} \mathrm{C}, \mu$ rose from about 0.5 at $10^{-6} \mathrm{~m} \mathrm{~s}^{-1}$ to a maximum at an intermediate velocity between $5 \times 10^{-5}$ and $10^{-4} \mathrm{~m} \mathrm{~s}^{-1}$, and then decreased rapidly to about 0.1 at $10^{-2} \mathrm{~m} \mathrm{~s}^{-1}$. The peak was more pronounced at the lower temperature. Curiously, the results of these tests on salt-water ice were similar to those found in friction experiments on freshwater granular ice tested under similar conditions using the same testing apparatus (Jones, 1989). The similarity suggests that brine pockets do not influence the kinetic friction coefficient significantly. (ii) Generally, the kinetic friction coefficient increased with decreasing temperature (e.g. at $v=10^{-4} \mathrm{~m} \mathrm{~s}^{-1}, \mu$ increased from 0.25 at $-3^{\circ} \mathrm{C}$ to 0.63 at $\left.-40^{\circ} \mathrm{C}\right)$.

The other noteworthy feature was the surface of the ice blocks. Following sliding under certain conditions, the surfaces exhibited a liquid film which formed droplets upon separation of the ice samples. This characteristic was present for all sliding velocities at temperatures $-3^{\circ} \mathrm{C}$ and $-10^{\circ} \mathrm{C}$, and for velocity $10^{-2} \mathrm{~m} \mathrm{~s}^{-1}$ at $-20^{\circ} \mathrm{C}$ and $-40^{\circ} \mathrm{C}$. For the fresh-water ice testing, the ice samples exhibited the surface droplets only at the sliding velocities $10^{-2} \mathrm{~m} \mathrm{~s}^{-1}$ at $-3^{\circ} \mathrm{C}$ and $5 \times 10^{-2} \mathrm{~m} \mathrm{~s}^{-1}$ at $-10^{\circ} \mathrm{C}$. The variation about the mean coefficient value for fresh-water ice was in general greater than that of saline ice under the same conditions, attributed to the lack of surface droplets.

\section{DISCUSSION}

Comparisons to previous work on the kinetic friction of ice are difficult, because the majority of the earlier work considered friction of ice against certain metals and plastic coating generally at higher sliding velocities.

The general decrease in the kinetic friction coefficient with both increasing velocity and increasing temperature has already been noted. Tabata and Tsushima (1979)

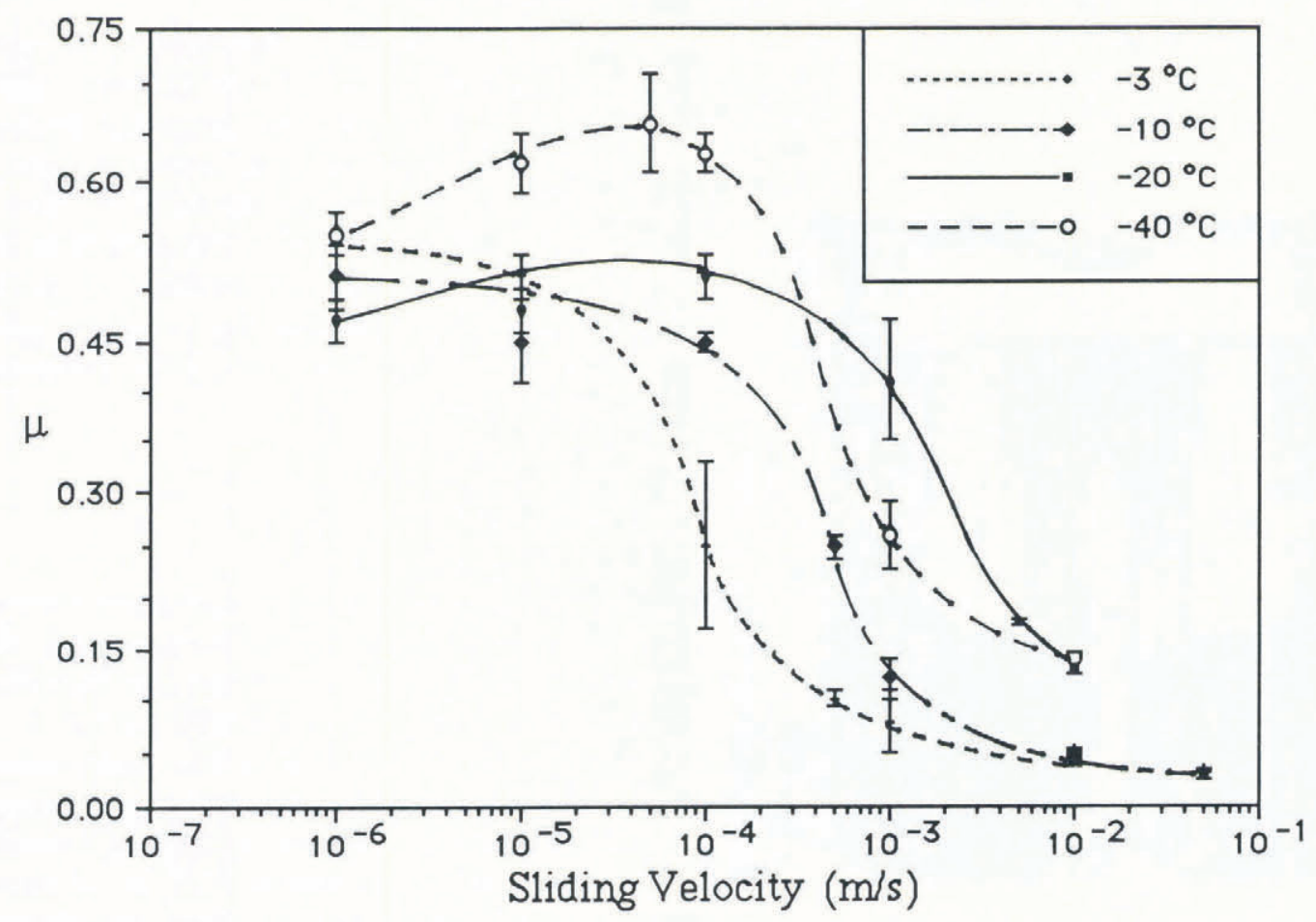

Fig. 4. Temperature dependence of kinetic friction of saline ice versus sliding velocity. 
observed these behaviors for steel moving beneath sea ice under $\sim 100 \mathrm{kPa}$ at $-5^{\circ} \mathrm{C}$ for the range $3.5 \times 10^{-7}$ $\leqslant v \leqslant 5 \times 10^{-2} \mathrm{~m} \mathrm{~s}^{-1}$. Saeki and others (1986) reported, for sea-ice sliding against both uncoated steel and concrete at $-8^{\circ} \mathrm{C}$ under $200 \mathrm{kPa}$, that $\mu$ decreases from 0.1 for steel and $\sim 0.2$ for concrete at $5 \times 10^{-4} \mathrm{~m} \mathrm{~s}^{-1}$ to a steady value of about 0.04 for both materials at $1.0 \mathrm{~m} \mathrm{~s}^{-1}$. Oksanen and Keinonen (1982) indicated, for frozen tap water sliding against itself at $\sim 2.5 \mathrm{kPa}$, that $\mu$ decreases from 0.038 at $0.5 \mathrm{~m} \mathrm{~s}^{-1}$ and $-15^{\circ} \mathrm{C}$ to 0.016 at $3 \mathrm{~m} \mathrm{~s}^{-1}$ and $-15^{\circ} \mathrm{C}$, and to 0.23 at $0.5 \mathrm{~m} \mathrm{~s}^{-1}$ and $-5^{\circ} \mathrm{C}$.

The curves in Figure 4, exhibiting peak values of kinetic friction coefficient at intermediate velocities at the lower temperatures $\left(-20^{\circ} \mathrm{C}\right.$ and $\left.-40^{\circ} \mathrm{C}\right)$, compare favorably with results obtained by Barnes and others (1971). They observed bell-shaped $\mu$ versus $v$ curves for polycrystalline fresh-water ice sliding on both polished granite and glass at about $1 \mathrm{MPa}$ normal pressure, $-18.5^{\circ} \mathrm{C} \leqslant T \leqslant-0.5^{\circ} \mathrm{C}$, and $10^{-8} \mathrm{~m} \mathrm{~s}^{-1} \leqslant v \leqslant 10^{-1} \mathrm{~m} \mathrm{~s}^{-1}$. Below $-10^{\circ} \mathrm{C}$, the ice adhered to the granite and, thus, at the lower temperatures the friction coefficient was for ice on ice. Coefficients reached a peak at $\sim 10^{-5} \mathrm{~m} \mathrm{~s}^{-1}$ for polished granite and at $\sim 10^{-2} \mathrm{~m} \mathrm{~s}^{-1}$ for glass, independent of temperature. Barnes and others (1971) attributed the peaks to a combination of processes, including creep, recrystallization, shearing of interfacial bonds and frictional heating. Their description does not fully explain the observations of the present study, in part because thin sections of tested saline specimens revealed no evidence of recrystallization. Instead, we propose the following explanation.

The friction force at the ice/ice interface originates within the real area of contact between asperities on the surfaces. A portion of the friction force can be attributed to adhesion; i.e. the making and breaking of bonds between contacting ice crystals. This contribution is nearly eliminated if a thin liquid film, acting as a lubricant, develops at the contact interface, through frictional heating and melting. This is probably responsible for the general decrease in the friction coefficient with increases in sliding velocity, as originally proposed by Bowden and Hughes (1939). In addition to the adhesive contribution to the friction, there is another important contributor: deformation of the contacting surfaces. Since both contacting surfaces have a finite roughness, asperities on the two specimens come into contact, or interlock, and must move by each other as sliding motion occurs. This may require deformation or fracture of one or both asperities. An important mechanism of deformation of ice is creep, with the creep rate increasing as the temperature approaches the melting point. A consideration of creep deformation can explain the shape of the friction versus velocity curve (Fig. 4) at low temperatures $\left(-20^{\circ}\right.$ to $\left.-40^{\circ} \mathrm{C}\right)$.

At the lowest sliding velocities, creep deformation of contacting asperities has time to occur before the asperities move past each other, even at low ambient temperatures. As the sliding velocity increases, however, the depressed creep rate at low temperatures does not allow the asperities to deform sufficiently during the time they are in contact, so an increased tangential force is required to shear the asperities. This is responsible for the peak in the friction coefficient at the low temperatures. If the velocity increases sufficiently, frictional heating increases the contact temperatures, resulting in higher creep rates and a decrease in the force required to deform the asperities. Eventually, at still higher velocities, melting of the asperity peaks occurs and the friction force drops more rapidly.

The above description of the sliding process is quite consistent with the sawtooth traces of the friction force versus time (and sliding distance) observed in this study, especially at low or intermediate sliding velocities (Fig. 3). The friction force would increase as the asperities interlocked and then decrease as they sheared or fractured.

The results of this work point out clearly the importance of temperature increases due to frictional heating. The temperature increases are related to the sliding velocity, the hardness of the ice (which influences the contact area), the thermal conductivity of the contacting materials and the friction coefficient. In addition, pressurized contact would cause a lowering in the melting point of the ice. Depression in the melting point, approximated by the Clausius-Clapeyron equation, would then reduce the amount of $\Delta T$ due to frictional heating necessary to produce melting. Although conditions were not sufficient to produce melting alone, calculations (Jones, 1989) indicated that, in conjunction, $\Delta T$ should be sufficient to cause surface melting for velocities $\geqslant 10^{-2} \mathrm{~m} \mathrm{~s}^{-1}$ at $T \leqslant-10^{\circ} \mathrm{C}$ and for $v \geqslant 10^{-3} \mathrm{~m} \mathrm{~s}^{-1}$ at $T=-3^{\circ} \mathrm{C}$.

\section{CONGLUSIONS}

The following conclusions were drawn from experiments on the kinetic friction of saline ice against itself:

(i) The kinetic friction coefficient, $\mu$, of salt-water ice was determined to be highly dependent upon the ambient test temperature (between $-3^{\circ}$ and $-40^{\circ} \mathrm{C}$ ) and the sliding velocity from $10^{-6}$ to $5 \times 10^{-2} \mathrm{~m} \mathrm{~s}^{-1}$. The velocity dependence was partitioned into three sections: one region of near constant $\mu$ (approximately 0.5 ) for velocities ranging from $10^{-6} \mathrm{~m} \mathrm{~s}^{-1}$ to about $10^{-5} \mathrm{~m} \mathrm{~s}^{-1}$; the transition zone, exhibiting a significant decrease in coefficient values for velocities between $10^{-5}$ and $10^{-3} \mathrm{~m} \mathrm{~s}^{-1}$, and the third region, where apparent frictional-heating effects result in steady and low ( 0.1 or less) values of $\mu$ at velocities $\geqslant 10^{-3} \mathrm{~m} \mathrm{~s}^{-1}$

(ii) The temperature dependence of the friction coefficients was manifested in two forms. A general increase in $\mu$ was measured for decreasing temperatures: at $10^{-4} \mathrm{~m} \mathrm{~s}^{-1}$ sliding velocity, for example, coefficients ranged from 0.25 at $-3^{\circ} \mathrm{C}$ to 0.63 at $-40^{\circ} \mathrm{C}$. At lower testing temperatures $\left(-20^{\circ} \mathrm{C}\right.$ and $\left.-40^{\circ} \mathrm{C}\right)$, the friction coefficient curves exhibited a peak value at a sliding velocity of approximately $5 \times 10^{-5} \mathrm{~m} \mathrm{~s}^{-1}$.

\section{ACKNOWLEDGEMENTS}

The work was supported by the Office of Naval Research, grant no. N00014-86K-0695, and was performed in the Ice Research Laboratory of the Thayer School of 
Fones and others: Kinetic friction of saline ice

Engineering. The laboratory is operated through the additional support of the Army Research Office, Minerals Management Service, U.S. Coast Guard, Amoco, Conoco, Exxon, Mobil, Shell, and Unocal.

\section{REFERENCES}

Barnes, P., D. Tabor, and J.C.F. Walker. 1971. The friction and creep of polycrystalline ice. Proc., R. Soc. London, Ser. A, 324(1557), 127-155.

Bowden, F.P. and T.P. Hughes. 1939. The mechanism of sliding on ice and snow. Proc. R. Soc. London, Ser. A, 172(949), 280-298.

Hopkins, M.A. and W.D. Hibler, III. 1989. On modeling the energetics of the ridging process. In Sinha, N.K., D.S. Sodhi, and J.S. Chung, eds.Proceedings of the Eighth International Conference on Offshore Mechanics and Arctic Engineering 1989 ... The Hague, The Netherlands, March 19 23, 1989. Vol. 4. Arctic and polar technology. New York, American Society of Mechanical Engineers, 175-178.

Jones, D.E. Unpublished. An experimental investigation of low-speed ice-ice friction. (Master of Engineering thesis, Dartmouth College. Thayer School of Engineering, 1989.)

Kuehn, G.A., R.W. Lee, W.A. Nixon, and E.M. Schulson. 1988. The structure and tensile behavior of first year sea ice and laboratory-grown saline ice. In Sodhi, D.S., C.H. Luk, and N.K. Sinha, eds. OMAE 1988 Houston. Proceedings of the Seventh International Conference on Offshore Mechanics and Arctic Engineering ... presented at ... Houston, Texas, February 7-12, 1988. Vol. 4. Arctic engineering and technology. New York, American Society of Mechanical Engineers, 11-17.

Oksanen, P. and J. Keinonen. 1982. The mechanism of friction of ice. Wear, 78, 315-324.

Saeki, H., T. Ono, N. Nakazawa, M. Sakai, and S. Tanaka. 1986. The coefficient of friction between sea ice and various materials used in offshore structures. $\mathcal{F}$. Energy Resour. Technol., 108, 65-71.

Schulson, E.M. 1990. The brittle compressive fracture of ice. Acta Metall. Materialia, 38, 1963-1976.

Tusima, K. and T. Tabata. 1979. Friction measurements of sea ice in flat plates of metals, plastics and coatings. POAC 79. The Fifth International Conference on Port and Ocean Engineering under Arctic Conditions at the Norwegian Institute of Technology, August 13-18, 1979. Proceedings. Vol. 1. Trondheim, University of Trondheim. Norwegian Institute of Technology, 741-755.

The accuracy of references in the text and in this list is the responsibility of the authors, to whom queries should be addressed. 